\title{
Eicosanoid production, thrombogenic ratio, and serum and LDL peroxides in normo- and hypercholesterolaemic post-menopausal women consuming two oleic acid-rich diets with different content of minor components
}

\author{
Pilar Oubiña ${ }^{1}$, Francisco J. Sánchez-Muniz ${ }^{1}$, Sofía Ródenas ${ }^{2}$ and Carmen Cuesta ${ }^{3}$ \\ ${ }^{1}$ Departamento de Nutrición y Bromatología I (Nutrición), Facultad de Farmacia, Universidad Complutense, \\ E-28040 Madrid, Spain \\ ${ }^{2}$ Sección Departamental de Química Analítica, Facultad de Farmacia, Universidad Complutense, E-28040 Madrid, Spain \\ ${ }^{3}$ Instituto de Nutrición y Bromatología, CSIC-UCM, Facultad de Farmacia, Universidad Complutense, E-28040 Madrid, \\ Spain
}

(Received 22 November 1999 - Revised 3 July 2000 - Accepted 21 July 2000)

\begin{abstract}
The present paper compares the effects of two monounsaturated oils, extra virgin olive oil (EVOO) and high-oleic acid sunflower oil (HOSO), on serum and LDL peroxides, eicosanoid production and the thrombogenic ratio (thromboxane (TX) $\mathrm{B}_{2}$ :6-keto-prostaglandin $\mathrm{F}_{1 \alpha}$ ) in fourteen non-obese post-menopausal women. The subjects, mean age 63 (SD 11) years, were assigned to two consecutive oleic acid-rich $28 \mathrm{~d}$ dietary periods. EVOO and HOSO represented $62 \%$ of the total lipid intake and were used as the only culinary fat during the first and second dietary periods respectively. Serum peroxides, plasma $\alpha$-tocopherol and $\mathrm{TXB}_{2}$ levels in stimulated platelet-rich plasma $\left(\mathrm{PRP}^{-\mathrm{TXB}_{2}}\right)$ were significantly higher $(P<0 \cdot 01, P<0 \cdot 001$, and $P<0.05$ respectively) after the HOSO diet than after the EVOO diet. The relationship between the serum cholesterol level $(<6.21 \mathrm{mmol} / \mathrm{l}$ or $\geq 6 \cdot 21 \mathrm{mmol} / \mathrm{l})$ and the type of dietary oil on eicosanoids, peroxides and $\alpha$-tocopherol were evaluated by two-way ANOVA. Dietary oil significantly affected $(P<0.05)$ the PRP-TXB 2 level, whereas serum and LDL peroxides were significantly affected $(P<0.001$ and $P<0.01$ respectively) by the serum cholesterol level. The plasma $\alpha$-tocopherol level was significantly affected by the serum cholesterol level and the type of dietary oil (both $P<0.001$ ). No significant relationships were found between serum cholesterol levels, serum peroxide or LDL peroxide levels, plasma $\alpha$-tocopherol concentrations or $\alpha$-tocopherol intakes with eicosanoid production or the thrombogenic ratio due to dietary changes. However, in spite of their higher $\alpha$-tocopherol levels, hypercholesterolaemic subjects showed increased peroxidation in serum and LDL in comparison with normocholesterolaemic subjects on the HOSO diet in comparison with the EVOO diet. These findings suggest that differences in the type of minor compounds, as well as in the concentration of linoleic acid, in both these monounsaturated oils may play an important role in modulating eicosanoid production and lipoprotein peroxidation when they constitute a large proportion of the diet of post-menopausal women.
\end{abstract}

Monounsaturated oils: Eicosanoid production: Lipoprotein peroxidation: $\alpha$-Tocopherol

In the UK, $\mathrm{CHD}$ is responsible for $23 \%$ of all female mortality (Office of Population Censuses and Surveys, 1993). Protective effects of oestrogen may be important in the prevention of $\mathrm{CHD}$, and consequently the risk of CHD increases in post-menopausal women due to decreased oestrogen synthesis (Williams, 1997).
The lower incidence of CHD in Mediterranean populations may be due to the high proportion of dietary monounsaturated fatty acids (MUFA), in relation to saturated fatty acids, consumed by the population of these countries (Keys et al. 1986). Although the traditional source of dietary MUFA in Mediterranean countries has

Abbreviations: EVOO, extra virgin olive oil; HOSO, high-oleic acid sunflower oil; MUFA, monounsaturated fatty acids; PG, prostaglandin; PRP, platelet-rich plasma; TX, thromboxane.

* Corresponding author: Professor Dr Francisco J. Sánchez-Muniz, fax + 3491 3941732, email frasan@eucmax.sim.ucm.es 
been olive oil, other sources of oils with similar fatty acid compositions but with different amounts and types of plant sterols, polyphenols, vitamins and other substances are available (Trichopoulou \& Lagiou, 1997).

Dietary fatty acid composition may have an effect on the development of thrombosis and atherosclerosis (Kwon et al. 1991; Knapp, 1997). Saturated fatty acids promote the formation of arterial thrombi; linoleic acid has been defined as anti-thrombotic, but oleic acid and other MUFA probably have little effect on arterial thrombosis (Kwon et al. 1991). However, controversial effects of linoleic acid on eicosanoid synthesis, which appeared to be dosedependent, have been described (Galli, 1992).

On the other hand, oxidised LDL have been found in human atherosclerotic lesions (Ylä-Hertuala et al. 1989). According to Holvoet \& Collen (1994) these particles and autoimmune antibodies against oxidised LDL may enhance the progression of these lesions by: (1) increasing platelet adhesion and aggregation, which may stimulate macrophage foam-cell generation and smooth-muscle cell proliferation; (2) triggering thrombosis; (3) impairing vasodilatation, which results in increased shear stress. Moreover, it has also been demonstrated that oxidised LDL decrease the secretion of endothelium-derived relaxing factor, resulting in enhanced platelet adhesion (Chin et al. 1992).

Hypercholesterolaemic patients show hyperaggregability and hypercoagulability (Miller, 1993; Sánchez-Muniz et al. 1998). The LDL of patients with CHD are more susceptible to oxidation, possibly as a result of a decreased amount of endogenous antioxidants (Holvoet \& Collen, 1994).

The purposes of the present study were: (1) to compare the effects of diet on eicosanoid production in post-menopausal women on a high-fat high-MUFA diet, containing either extra virgin olive oil (EVOO) or high-oleic acid sunflower oil (HOSO); (2) to assess whether the effects of the diets on thrombogenesis also depend on serum cholesterol levels; (3) to study the possible relationship between eicosanoid production and serum and LDL peroxides.

\section{Material and methods}

\section{Subjects}

Nuns from an enclosed convent were studied. The subjects were chosen because of their regular lifestyle, age and dietary habits. Fifteen women were initially enrolled in the study, but one was later excluded because she was premenopausal. The mean age of the fourteen subjects who finished the study was 63 (SD 11) years. The mean body weight of the subjects was 54.3 (SD 9.3) $\mathrm{kg}$ and the mean BMI was $23 \cdot 2(\mathrm{SD} 3 \cdot 4) \mathrm{kg} / \mathrm{m}^{2}$. No subject reported any previous cardiovascular, metabolic or systemic disease or took any drug that might affect lipid metabolism or platelet aggregation. The study protocol was approved by the Spanish Comisión Interministerial de Ciencia y Tecnología, and performed in accordance with the Helsinki Declaration.

\section{Experimental design}

Subjects were assigned to two consecutive $28 \mathrm{~d}$ periods when they received diets rich in EVOO and HOSO. There was no washout period between experimental diets because according to Keys et al. (1965) diet induces stable changes in lipoprotein-lipids after 4 weeks and the average lifespan of circulating platelets is less than 2 weeks (Paulus \& Aster, 1985).

\section{Diets}

The diet of the community was assessed using the precise weighing method (Marr, 1971). All ingredients used in the preparation of dishes, as well as the inedible waste, were weighed. The cooked weights of individual portions and table waste were also recorded. Energy and nutrient intakes were calculated using food composition tables for the raw weights of foodstuffs (Moreiras et al. 1996). Two dietitians were present every day in the community's kitchen during the preparation of meals. A $14 \mathrm{~d}$ menu cycle was used.

Body weight was measured twice weekly and energy intake adjusted as needed to maintain the initial weight. To avoid radical dietary changes that would stress participants, subjects were assigned to two consecutive $28 \mathrm{~d}$ dietary periods, in which menus and individual ratios were kept constant with respect to the regular diet. The regular diet contained, as culinary fat, a homogenous mix $(1: 1, \mathrm{v} / \mathrm{v})$ of olive oil and refined sunflower oil. The single distinguishing feature of the experimental diets was the oleic acid-rich oil used. In the first period all subjects consumed a diet rich in EVOO (Comunal Olivarera Mora, Toledo, Spain). This period was followed by a second period rich in HOSO (Koipe Co., Andújar, Spain). Both these oils were used raw as well as for cooking. A high percentage of the oils (about 45) was consumed raw in salad dressing, while the rest was used for sautéing, frying and pot-roasting, and in the preparation of fish, eggs, vegetables and stews.

The percentage of oleic acid (18:1n-9) in EVOO and HOSO was similar; however, EVOO contained more palmitic acid (16:0) and less linoleic acid (18:2n-6) than HOSO (Table 1). Total polyphenol, squalene and $\Delta^{5}$ avenasterol concentrations were $4,9 \cdot 2$, and 2.7 times higher respectively in the EVOO, while total sterols, $\beta$-sitosterol

Table 1. Composition of extra virgin olive oil (EVOO) and high-oleic acid sunflower oil (HOSO)

\begin{tabular}{lcc}
\hline & EVOO & HOSO \\
\hline Major fatty acids (mg/100 mg total fatty acids) & \\
Palmitic acid & $9 \cdot 6$ & 4.5 \\
Oleic acid & 74.0 & 73.5 \\
Linoleic acid & $7 \cdot 1$ & $15 \cdot 0$ \\
SFA & $14 \cdot 1$ & $9 \cdot 1$ \\
MUFA & 74.7 & $75 \cdot 0$ \\
PUFA & $11 \cdot 2$ & $15 \cdot 0$ \\
& & \\
Minor components (mg/kg oil) & & \\
$\alpha$-Tocopherol & $192 \cdot 7$ & $538 \cdot 0$ \\
Total polyphenols & $108 \cdot 0$ & $25 \cdot 0$ \\
Total sterols & 1457 & 3941 \\
Campesterol & $45 \cdot 3$ & $340 \cdot 5$ \\
$\beta$-Sitosterol & 1217 & 2101 \\
$\Delta^{5}$-Avenasterol & $117 \cdot 7$ & $66 \cdot 6$ \\
Squalene & 4600 & 500 \\
\hline
\end{tabular}

SFA, saturated fatty acids; MUFA, monounsaturated fatty acids; PUFA, polyunsaturated fatty acids. 
and $\alpha$-tocopherol levels were 2.7, 1.7 and $2 \cdot 6$ times higher respectively in the HOSO. MUFA contribute about $28 \%$ energy in both diets, but linoleic acid was $45 \%$ lower in the EVOO diet than in the HOSO diet.

\section{Laboratory analyses}

The fatty acid composition of the oils was analysed using a Hewlett-Packard 5890 Series II gas chromatograph (Palo Alto, CA, USA). Reverse-phase HPLC (Hess et al. 1991) was used for $\alpha$-tocopherol determination, and total polyphenols were determined using the method of FolinCiocalteau (Singleton \& Rossi, 1965). Other minor components were determined in the non-saponifiable fraction of the oils by GC (Las Comunidades Europeas, 1991).

After overnight fasting (12 h), blood samples were collected by venepuncture. Blood was collected with minimum intrusion after the anthropometric evaluation to avoid stress to the volunteers. A vacuum system was not used, although it allows quicker blood extraction, because it can cause platelet damage and greater blood vessel stress. According to Subbiah et al. (1991) to avoid damage to platelets the first $10 \mathrm{ml}$ blood should be not used for thromboxane analysis. Thus, we used the first $10 \mathrm{ml}$ for biochemical analyses and the remainder of the sample for eicosanoid analyses. Moreover, because endothelial cells can be stressed by venepuncture, potentially affecting the blood determination of prostacyclin, we determined this eicosanoid only in the urine.

Total cholesterol in serum was determined using a Technicon RA-500 AutoAnalyzer (Tarrytown, NY, USA) by the enzymic esterase-cholesterol oxidase method of Boehringer Mannheim Gmbtt, Mannheim, Germany.

Lipoproteins were isolated density-gradient ultracentrifugation for $22 \mathrm{~h}$ using the salt gradient composition suggested by Terpstra et al. (1981) followed by removal of the salt. However, an ultracentrifugation temperature of $8^{\circ} \mathrm{C}$ was used instead of $20^{\circ} \mathrm{C}$ to minimise thermal damage to lipoproteins.

Serum peroxide and LDL peroxide concentrations were determined as thiobarbituric acid-reactive substances according to the method of Yagi (1993).

The platelet-rich plasma (PRP) was separated from anticoagulated blood, and ADP-stimulated thromboxane (TX) $\mathrm{A}_{2}$ synthesis was measured in PRP. At the end of each dietary period $24-\mathrm{h}$ urine samples were collected. $\mathrm{TXB}_{2}$, a stable metabolite of $\mathrm{TXA}_{2}$, was extracted from PRP and urine samples, while 6-keto-prostaglandin (PG) $F_{1 \alpha}$, a stable metabolite of prostacyclin $\mathrm{I}_{2}\left(\mathrm{PGI}_{2}\right)$ was extracted from urine by the procedures of Powell (1980). These metabolites were determined using ${ }^{125}$ I-labelled radioimmunoassay kits purchased from Advanced Magnetics Inc. (Cambridge, MA, USA).

\section{Statistical analyses}

The paired Student's $t$ test was used to assess the effects of both oils on serum and LDL peroxidation, plasma $\alpha$ tocopherol and PRP-TXB ${ }_{2}$ production, and $24 \mathrm{~h}$ urinary $\mathrm{TXB}_{2}$ and 6-keto-PGF ${ }_{1 \alpha}$ excretion. Two-way ANOVA was
Table 2. Daily intake of post-menstrual women during the extra virgin olive oil (EVOO) dietary period and the high-oleic acid sunflower oil (HOSO) dietary period $\dagger$

(Mean values and standard deviations for fourteen women. Values are expressed as a percentage of the total energy intake, except where stated)

\begin{tabular}{|c|c|c|c|c|}
\hline & \multicolumn{2}{|c|}{ EVOO diet } & \multicolumn{2}{|c|}{ HOSO diet } \\
\hline & Mean & SD & Mean & SD \\
\hline Energy $(\mathrm{kJ} / \mathrm{d})$ & 7347 & 775 & 7347 & 775 \\
\hline Protein & 11.7 & 0.4 & 11.7 & 0.4 \\
\hline Carbohydrates & $42 \cdot 1$ & $3 \cdot 0$ & $42 \cdot 1$ & 3.0 \\
\hline Lipids & $46 \cdot 2$ & $3 \cdot 0$ & $46 \cdot 2$ & $3 \cdot 0$ \\
\hline SFA & $11 \cdot 8$ & 1.7 & $10 \cdot 3^{*}$ & 1.7 \\
\hline MUFA & $28 \cdot 5$ & 1.7 & $27 \cdot 8$ & $1 \cdot 6$ \\
\hline PUFA & $2 \cdot 8$ & 0.1 & $4 \cdot 6^{\star}$ & 0.2 \\
\hline \multicolumn{5}{|l|}{ Major fatty acids } \\
\hline Palmitic acid & $6 \cdot 6$ & 0.7 & $5 \cdot 0^{*}$ & 0.7 \\
\hline Oleic acid & $27 \cdot 5$ & 1.6 & $27 \cdot 0$ & 1.6 \\
\hline Linoleic acid & $2 \cdot 2$ & $0 \cdot 1$ & $4 \cdot 0^{*}$ & 0.2 \\
\hline Linolenic acid & 0.37 & 0.04 & 0.32 & 0.04 \\
\hline Eicosapentaenoic acid & 0.05 & 0.01 & 0.05 & 0.01 \\
\hline Docosapentaenoic acid & 0.02 & 0.00 & 0.02 & 0.00 \\
\hline Docosahexaenoic acid & 0.09 & 0.01 & 0.09 & 0.01 \\
\hline Cholesterol (mg/d) & $401 \cdot 4$ & 33.9 & 401.4 & $33 \cdot 9$ \\
\hline Fibre (g/d) & $16 \cdot 5$ & $2 \cdot 1$ & $16 \cdot 5$ & $2 \cdot 1$ \\
\hline
\end{tabular}

SFA, saturated fatty acids; MUFA, monounsaturated fatty acids; PUFA, polyunsaturated fatty acids.

Mean values were significantly different from those for EVOO diet: ${ }^{\star} P<0.05$. † For details of subjects, diets and procedures, see p. 42 and Table 1.

used to assess the effects of each oil in women with a total cholesterol level $<6.21 \mathrm{mmol} / \mathrm{l}$ compared with those with a total cholesterol level of $\geq 6.21 \mathrm{mmol} / 1$ on these variables.

\section{Results}

Dietary assessment

Food intake was the same throughout both dietary periods (Table 2). Fats and oils contributed two-thirds of the total lipids in both experimental periods, and the experimental oils provided approximately $62 \%$ of the total fat intake in each case. The energy contribution of palmitic and linoleic acids, however, as well as the amount of $\alpha$-tocopherol consumed, was significantly different $(P<0.05$ in each case) between the two dietary periods. The average daily fibre intake was $16.5 \mathrm{~g}$, while that of cholesterol was approximately $400 \mathrm{mg}$.

\section{Serum peroxides, LDL peroxides and plasma $\alpha$-tocopherol}

Table 3 shows that the women displayed higher total lipid peroxide concentrations $(P<0.01)$ following the HOSO diet than after the EVOO diet. No differences were found for LDL peroxides. Statistical analysis (two-way ANOVA) showed a highly significant effect of the blood cholesterol level on serum peroxides and LDL peroxides $(P<0.001$ in both cases), whereas the type of dietary oil did not significantly affect those variables. No significant interaction between the cholesterol level and the dietary oil was found (Table 4).

At the end of the HOSO period $\alpha$-tocopherol levels were significantly higher $(P<0.001)$ than those at the 
Table 3. Concentration of thromboxane $(T X) B_{2}$ in platelet-rich plasma (PRP) and urine, 6-ketoprostaglandin $(P G) F_{1 \alpha}$ in urine, thrombogenic ratio $\left(\mathrm{TXB}_{2}: 6\right.$-keto- $\left.\mathrm{PGF}_{1 \alpha}\right)$ in urine and lipid peroxidation in serum of post-menopausal women consuming extra virgin olive oil (EVOO) and high-oleic acid sunflower oil (HOSO) $\dagger$

(Mean values and standard deviations for fourteen women)

\begin{tabular}{|c|c|c|c|c|}
\hline & \multicolumn{2}{|c|}{ EVOO diet } & \multicolumn{2}{|c|}{ HOSO diet } \\
\hline & Mean & SD & Mean & SD \\
\hline Platelets $\left(/ \mathrm{mm}^{3}\right)$ in PRP & 298214 & 43773 & 280857 & 67837 \\
\hline $\mathrm{TXB}_{2}$ in PRP (pg/ $10^{8}$ platelets) & 584.3 & $356 \cdot 3$ & $698.5^{*}$ & $369 \cdot 4$ \\
\hline Urinary volume (litres) & $1 \cdot 19$ & 0.29 & 1.07 & 0.27 \\
\hline $\mathrm{TXB}_{2}$ in urine: $\mathrm{pg} / \mathrm{ml}$ & $871 \cdot 0$ & 383.7 & $901 \cdot 6$ & $306 \cdot 1$ \\
\hline $\mathrm{pg} / \mathrm{min}$ & $666 \cdot 1$ & 241.8 & 648.5 & $213 \cdot 3$ \\
\hline 6-keto-PGF $F_{1 \alpha}$ in urine: $\mathrm{pg} / \mathrm{ml}$ & $1044 \cdot 8$ & $333 \cdot 2$ & $990 \cdot 7$ & $216 \cdot 7$ \\
\hline $\mathrm{pg} / \mathrm{min}$ & $816 \cdot 1$ & $150 \cdot 6$ & $720 \cdot 4$ & $164 \cdot 8$ \\
\hline $\mathrm{TXB}_{2}: 6$-keto-PGF ${ }_{1 \alpha}$ in urine & 0.82 & 0.26 & 0.91 & 0.23 \\
\hline Serum total lipid peroxides $\ddagger(\mathrm{nmol} / \mathrm{ml})$ & 0.87 & 0.73 & $0.95^{* *}$ & 0.70 \\
\hline LDL peroxides $\ddagger(\mathrm{nmol} / \mathrm{ml})$ & 0.28 & 0.21 & 0.29 & 0.22 \\
\hline$\alpha$-Tocopherol $(\mathrm{mmol} / \mathrm{l})$ & 28.6 & $6 \cdot 4$ & 34.4 *** & $5 \cdot 4$ \\
\hline
\end{tabular}

Mean values were significantly different from those for EVOO diet: ${ }^{\star} P<0.05,{ }^{\star \star} P<0.01,{ }^{\star \star \star} P<0.01$.

$\dagger$ For details of subjects, diets and procedures, see p. 42 and Table 1.

¥ Determined as thiobarbituric acid-reactive substances, according to the method of Yagi (1993)

end of the EVOO period for all subjects (Table 3). Statistical analysis (two-way ANOVA) showed a highly significant effect of both the serum cholesterol level and the type of dietary oil on $\alpha$-tocopherol levels $(P<0.001$ in both cases). However, there was no significant interaction between serum cholesterol level and type of dietary oil (Table 4).

\section{Thromboxane $B_{2}$ in ADP-stimulated platelet-rich plasma}

$\mathrm{TXB}_{2}$ concentration in PRP was significantly lower $(P<$ $0.05)$ in the women after consuming the EVOO diet than after the HOSO diet (Table 3). Statistical analysis (two-way ANOVA) showed that the type of dietary oil had a significant effect $(P<0.05)$ on $\mathrm{TXB}_{2}$ concentration in PRP (Table 4).

\section{Eicosanoids in urine and the thrombogenic ratio}

The urinary excretion of $\mathrm{TXB}_{2}$ and 6-keto-PGF ${ }_{1 \alpha}$ (expressed as $\mathrm{pg} / \mathrm{ml}$ and $\mathrm{pg} / \mathrm{min}$ ) and the thrombogenic ratio $\mathrm{TXB}_{2}: 6$ keto-PGF ${ }_{1 \alpha}$ are shown in Table 3 . These were no significant differences between the types of dietary oil for any of these variables. Statistical analysis (two-way ANOVA) showed no significant effect of the serum cholesterol level or the type of dietary oil was found (Table 4).

\section{Discussion}

\section{Dietary assessment}

The concentrations of polyphenols, total and individual sterols, and squalene were rather different in EVOO and HOSO. Both diets presented the same energy profile and

Table 4. Serum cholesterol level and concentration of thromboxane (TX) $B_{2}$ in platelet-rich plasma (PRP) and urine, 6-keto-prostaglandin (PG) $\mathrm{F}_{1 \alpha}$ in urine, thrombogenic ratio $\left(\mathrm{TXB}_{2}: 6\right.$-keto-PGF $\left.\mathrm{F}_{1 \alpha}\right)$ in urine and lipid peroxidation in serum of normocholesterolaemic $(<6 \cdot 21 \mathrm{mmol} / \mathrm{l})$ or hypercholesterolaemic ( $\geq 6.21 \mathrm{mmol} / \mathrm{l})$ post-menopausal women consuming diets rich in extra virgin olive oil (EVOO) or high-oleic acid sunflower oil (HOSO)*

(Mean values, and standard deviations for seven women per group)

\begin{tabular}{|c|c|c|c|c|c|c|c|c|c|c|c|}
\hline \multirow{3}{*}{$\begin{array}{l}\text { Serum cholesterol } \\
\qquad(\mathrm{mmol} / \mathrm{l}) \ldots\end{array}$} & \multicolumn{4}{|c|}{ EVOO diet } & \multicolumn{4}{|c|}{ HOSO diet } & \multicolumn{3}{|c|}{ Statistical significance (two-way ANOVA) of: } \\
\hline & \multicolumn{2}{|c|}{$<6.21$} & \multicolumn{2}{|c|}{$\geq 6.21$} & \multicolumn{2}{|c|}{$<6.21$} & \multicolumn{2}{|c|}{$\geq 6.21$} & \multirow{2}{*}{$\begin{array}{l}\text { Effect of } \\
\text { oil type }\end{array}$} & \multirow{2}{*}{$\begin{array}{c}\text { Effect of } \\
\text { serum } \\
\text { cholesterol level }\end{array}$} & \multirow[b]{2}{*}{ Interaction } \\
\hline & Mean & SD & Mean & SD & Mean & SD & Mean & SD & & & \\
\hline $\begin{array}{l}\mathrm{TXB}_{2} \text { in PRP }\left(\mathrm{pg} / 10^{8}\right. \\
\text { platelets) }\end{array}$ & $592 \cdot 8$ & 393.6 & $572 \cdot 9$ & 336.5 & $755 \cdot 6$ & 428.9 & $622 \cdot 4$ & 291.6 & $P<0.05$ & NS & NS \\
\hline $\mathrm{TXB}_{2}$ in urine $(\mathrm{pg} / \mathrm{min})$ & $714 \cdot 4$ & $255 \cdot 8$ & $601 \cdot 6$ & $222 \cdot 4$ & $676 \cdot 9$ & $225 \cdot 6$ & $620 \cdot 0$ & $214 \cdot 1$ & NS & NS & NS \\
\hline $\begin{array}{l}\text { 6-keto-PGF }{ }_{1 \alpha} \text { in urine } \\
(\mathrm{pg} / \mathrm{min})\end{array}$ & $792 \cdot 3$ & 173.4 & 847.9 & $121 \cdot 6$ & $737 \cdot 4$ & $171 \cdot 1$ & $667 \cdot 3$ & 151.6 & NS & NS & NS \\
\hline $\mathrm{TXB}_{2}$ : 6-keto-PGF ${ }_{1 \alpha}$ in urine & 0.91 & 0.26 & 0.70 & 0.23 & $0 \cdot 87$ & 0.18 & 0.94 & 0.28 & NS & NS & NS \\
\hline $\begin{array}{l}\text { Serum total lipid peroxides } \\
(\mathrm{nmol} / \mathrm{ml})\end{array}$ & 0.39 & 0.26 & 1.50 & 0.68 & 0.50 & 0.24 & 1.54 & 0.68 & NS & $P<0.001$ & NS \\
\hline LDL peroxides† (nmol/ml) & 0.17 & 0.07 & 0.42 & 0.25 & 0.17 & 0.08 & 0.45 & 0.25 & NS & $P<0.01$ & NS \\
\hline$\alpha$-Tocopherol (mmol/l) & $24 \cdot 8$ & 5.4 & 33.6 & 3.5 & 31.4 & $4 \cdot 8$ & 38.5 & $3 \cdot 3$ & $P<0.001$ & $P<0.001$ & NS \\
\hline
\end{tabular}

* For details of subjects, diets and procedures, see p. 42 and Table 1.

† Determined as thiobarbituric acid-reactive substances, according to the method of Yagi (1993). 
cholesterol content, and were very rich in MUFA but the energy contributions of palmitic and linoleic acids were lower and higher respectively in the EVOO diet than in the HOSO diet. It has been reported that minor dietary components have potential effects on lipoprotein peroxidation (Chimi et al. 1991; Montedoro et al. 1992), and on platelet aggregation and eicosanoid production (Petroni et al. 1994; Sánchez-Muniz et al. 1998). This factor was taken into account when considering both the fatty acid profile of the diets and the levels of minor components in the oils.

\section{Serum peroxide, LDL peroxide and $\alpha$-tocopherol levels}

A large percentage of women (71) had increased serum lipid peroxide levels after the HOSO dietary period compared with the levels found at the end of the EVOO dietary period. These results seem paradoxical considering both the higher $\alpha$-tocopherol content of the HOSO diet and the higher $\alpha$-tocopherol levels in plasma at the end of the HOSO dietary period.

$\Delta^{5}$-Avenasterol and other sterols are potent antioxidants, while squalene has a moderate antioxidant effect (Boskou, 1999). Moreover, antioxidant properties have been shown in some polyphenols present in EVOO (e.g. 2-(3,4dihydroxyphenyl) ethanol, oleuropeine glycoside, $p$-hydroxyphenyl ethanol, tyrosol; Montedoro et al. 1992). The lower content of such minor components, together with the higher linoleic acid level in HOSO, would account for the significantly higher serum levels of TBARS found in the women after the HOSO diet compared with that observed after the EVOO diet. However, although in the present study no data are available on tocopherol or antioxidant distribution in lipoproteins; the results show that prooxidant-antioxidant mechanisms resulted in similar LDL peroxidation levels following both dietary periods.

According to our data, a high proportion of peroxides is associated with lipoproteins other than LDL (e.g. VLDL, lipoprotein(a) and HDL). This finding is in agreement with the findings of Szczeklik \& Gryglewski (1980) and Hagihara et al. (1984) relating to TBARS in human lipoproteins. Solà et al. (1997) studied the influence of dietary fat on the oxidation of HDL particles. These authors found that a diet rich in oleic acid (18:1) produced $\mathrm{HDL}_{3}$ that contain more $18: 1$ and TBARS than the $\mathrm{HDL}_{3}$ produced following a diet rich in linoleic acid (18:2). Moreover, TBARS in those particles correlated negatively with the 18:1:18:2 value and positively with the 18:1 content of phospholipids.

Higher serum and LDL peroxide levels were found in hypercholesterolaemic women following both diets. This finding suggests a higher susceptibility of LDL to oxidation. According to Holvoet \& Collen (1994) the higher susceptibility of LDL to oxidation in patients with CHD would be a result of fatty acid composition of the LDL particles as well as reduced endogenous antioxidants such as vitamin E. However, hypercholesterolaemic women had higher plasma vitamin E levels, which would prevent the increase in peroxidation. With the aim of finding a possible explanation, serum total lipid peroxides: $\alpha$-tocopherol was calculated (data not shown).
Normocholesterolaemic subjects had a ratio of 0.016 after both diets, while for hypercholesterolaemic subjects the ratio was 0.045 and 0.040 after EVOO and HOSO diets respectively, suggesting that hypercholesterolaemic subjects are more susceptible to peroxidation than normocholesterolaemic subjects.

\section{Thromboxane $B_{2}$ level in ADP-stimulated platelet-rich plasma, and excretion of urinary eicosanoids}

Platelet aggregation is modulated by the production of $\mathrm{TXA}_{2}$ and $\mathrm{PGI}_{2}$. An optimal balance of $\mathrm{TXA} \mathrm{A}_{2}-\mathrm{PGI}_{2}$ may be important in prevention of thrombotic conditions. Evidence indicates that dietary fatty acids can alter this balance (Knapp, 1997).

On stimulation platelets produce $\mathrm{TXA}_{2}$. Thus, the measurement of the platelet $\mathrm{TXB}_{2}$ level in vitro assesses the capacity for $\mathrm{TXA}_{2}$ production under maximum stimulation. On the other hand, measurement of $\mathrm{TXB}_{2}$ in urine is considered to be an acceptable and non-invasive estimate of in vivo production (Mensink et al. 1999). Thus, the level of the stable metabolite of $\mathrm{PGI}_{2}\left(6-\mathrm{keto}^{-} \mathrm{PGF}_{1 \alpha}\right)$ was also determined to assess the effect of the diets on $\mathrm{TXA}_{2}: \mathrm{PGI}_{2}$.

About $80 \%$ of the women showed lower PRP-TXB levels after the EVOO diet than after the HOSO diet. The effect of polyunsaturated fatty acids on eicosanoid synthesis is controversial and highly dose dependent. According to Galli (1992), at levels between 0 and 5-6\% total energy intake linoleic acid enhances the platelet formation of eicosanoids derived from arachidonic acid. The energy contribution of linoleic acid in both experimental diets was $<5 \%$, but the linoleic acid content was about twice as high in the HOSO diet as that in the EVOO diet, explaining why $\mathrm{TXB}_{2}$ levels were higher at the end of the HOSO dietary period.

Small differences in other fatty acids between diets would also cause variations in PRP-TXA 2 synthesis. The higher $n-6: n-3$ fatty acids or the higher linoleic acid: $\alpha$ linolenic acid in the HOSO diet may partially explain the greater PRP-TXB ${ }_{2}$ level following this diet. Experimental and clinical studies have shown that there is competition between linoleic and $\alpha$-linolenic acids in relation to the $\Delta^{6}$ desaturase enzyme system (Knapp, 1997).

Differences in the concentrations of minor components of the two oils may also account for some of the differences observed in $\mathrm{TXB}_{2}$ levels in stimulated PRP after the two dietary periods. According to Petroni et al. (1994) the incubation of PRP with 2-(3,4-dihydroxyphenyl) ethanol before collagen stimulation, resulted in about a $70 \%$ reduction in the $\mathrm{TXB}_{2}$ level. In agreement with the present results, in a previous study using the same subjects lower platelet aggregation was found after an EVOO diet than after a HOSO diet (Sánchez-Muniz et al. 1998).

Urinary $\mathrm{TXB}_{2}$ or $\mathrm{PGI}_{2}$ levels were not affected by the either the type of dietary oil or the serum cholesterol level. Urinary $\mathrm{TXB}_{2}$ measurement provides time-integrated information about in vivo $\mathrm{TXA}_{2}$ biosynthesis (Mensink et al. 1999). However, although a considerable proportion of urinary $\mathrm{TXA}_{2}$ is derived from $\mathrm{TXA}_{2}$ synthesised by platelets (FitzGerald et al. 1987), the urinary concentrations 
of $\mathrm{TXA}_{2}$ may be confounded by the eicosanoid production of the kidney. This factor may explain the different results for PRP-TXB ${ }_{2}$ and urinary $\mathrm{TXB}_{2}$ levels found after the two dietary periods. However, the synthesis of $\mathrm{PGI}_{2}$ by the aortas of animals eating a diet with more than $40 \mathrm{~g}$ linoleic $\mathrm{acid} / \mathrm{kg}$ is lower than or identical to that of animals eating a diet with less than $40 \mathrm{~g}$ linoleic acid/kg (Szczeklik et al. 1985), explaining the absence of significance found for $\mathrm{PGI}_{2}$ between the two dietary periods in the current study.

In conclusion, although EVOO and HOSO are defined as monounsaturated oils, they show differences in the content of other fatty acids (e.g. palmitic and linoleic acids) and in minor components that account for the different results seen in serum peroxide and plasma $\alpha$-tocopherol levels and PRP-TXB ${ }_{2}$ production. Further studies are necessary in order to understand the different physiological effects induced by the ingestion of EVOO and HOSO, and to assess the role of some minor components present in these oils.

\section{Acknowledgements}

This study was supported by the Spanish Comisión Interministerial de Ciencia y Tecnología (CICYT) Project ALI-92-0289-CO2-01. The authors are indebted to the Carmelitas Descalzas (Lerma, Burgos, Spain) for their contribution. We also thank Hoffmann La Roche (Basel, Switzerland), Koipe (Andujar, Spain), Laura Barrios, Ana Sánchez, Teresa Ruiz-Pérez, and Dr Melchor Ruiz for their advice and assistance.

\section{References}

Boskou D (1999) Non-nutrient antioxidants and stability of frying oils. In Frying of Foods. Oxidation, Nutrient and Non-nutrient Antioxidants, Biologically Active Compounds and High Temperatures, pp. 183-204 [D Boskou and I Elmadfa, editors]. Lancaster and Basel: Technomic Publishing Co, Inc.

Chimi HJ, Cillard J, Cillard P \& Rahmani M (1991) Peroxyl and hydroxyl radical scavenging activity of some natural antioxidants. Journal of the American Oil Chemist's Society 68 , 307-312.

Chin JH, Azhar S \& Hoffman BB (1992) Inactivation of endothelial derived relaxing factor by oxidized lipoproteins. Journal of Clinical Investigation 89, 10-18.

FitzGerald GA, Healy C \& Daugherty J (1987) Thromboxane $\mathrm{A}_{2}$ biosynthesis in human disease. Federation Proceedings 46, $154-158$

Galli C (1992) Membrane and essential fatty acids (except for the neural system). In Essential Fatty Acids and Infant Nutrition, pp. 3-10 [J Ghisolfi and G Putet, editors]. Paris: John Libbey Eurotext.

Hagihara M, Nishagaki I, Maseki M \& Yagi K (1984) Agedependent changes in lipid peroxide levels in the lipoprotein fraction of human serum. Journal of Gerontology 39, 269-272.

Hess D, Keller HE, Oberlin B, Bonfanti R \& Schüep W (1991) Simultaneous determination of retinol, tocopherols, carotenes and lycopene in plasma by means of high-performance liquid chromatography on reverse phase. Journal of Vitamin and Nutrition Research 61, 232-238.

Holvoet P \& Collen D (1994) Oxidized lipoproteins in atherosclerosis and thrombosis. FASEB Journal 8, 1279-1284.

Keys A, Anderson JT \& Grande F (1965) Serum cholesterol response to changes in diet IV. Particular saturated fatty acids in the diet. Metabolism 14, 776-787.

Keys A, Menotti A, Karvonen MJ, Aravanis C, Blackburn H, Buzina R, Djordjevic BS, Dontas AS, Fidanza F, Keys MH, Kromhout D, Nedeljkovic S, Punsar S, Seccareccia F \& Toshima H (1986) The diet and 15-year death rate in the Seven Countries Study. American Journal of Epidemiology 124, $903-$ 915.

Knapp HR (1997) Dietary fatty acids in human thrombosis and haemostasis. American Journal of Clinical Nutrition $\mathbf{6 5}$, Suppl.1687S-1698S

Kwon JS, Snook JT, Wardlow GM \& Hwang DH (1991) Effects of diets high in saturated fatty acids, canola oil, or safflower oil on platelet function, thromboxane $\mathrm{B}_{2}$ formation, and fatty acid composition of platelet phospholipids. American Journal of Clinical Nutrition 54, 341-348.

Las Comunidades Europeas (1991) Diario Oficial de Las Comunidades Europeas. Anexo V. Determinación de la Composición y del Contenido de Esteroles Mediante Cromatografía de Gases con Columna Capilar (Official Journal of the European Communities. Annexe V. Determination of Sterol Composition and Content by Capilar Gas Chromatography). Publication no. L248/15-22. Luxemburg: Oficina de las Publicaciones Oficiales de las Comunidades Europeas.

Marr JW (1971) Individual dietary surveys: purposes and methods. World Review of Nutrition and Dietetics 13, 105-164.

Mensink RP, Houwelingen AC, van Kromhout D \& Hornstra G (1999) A vitamin E concentrate rich in tocotrienols had no effect on serum lipids, lipoproteins, or platelet function in men with mildly elevated serum lipid concentration. American Journal of Clinical Nutrition 69, 213-219.

Miller GJ (1993) Hyperlipidaemia and hypercoagulability. Progress in Lipid Research 32, 61-69.

Montedoro GF, Servili M, Baldioli M \& Miniati E (1992) Simple and hydrolyzable phenolic compounds in virgin olive oil. Their extraction, separation and quantitative and semiquantitative evaluation by HPLC. Journal of Agricultural and Food Chemistry 40, 1571-1576.

Moreiras O, Carbajal A \& Cabrera L (1996) Tablas de Composición de Alimentos (Food Composition Tables). Madrid, Spain: Ediciones Pirámides.

Office of Population Censuses and Surveys (1993) Deaths from Coronary Heart Disease/100,000 for Males and Females aged 35-44, 45-54 and 55-64 in England and Wales, in Scotland and in Northern Ireland in the Years 1950-51 to 1986-87. London: HM Stationery Office.

Paulus JM \& Aster RH (1985) Production distribution, life-span and fate of platelets. In Hematology, 3rd ed., p. 1185 [WJ Williams, E Beutler, AJ Erslev and MA Lichtman, editors]. New York: McGraw Hill.

Petroni A, Blasevich M, Salami M, Servili M, Montedoro GF \& Galli C (1994) A phenolic antioxidant extracted from olive oil inhibits platelet aggregation and arachidonic acid metabolism in vitro. World Review of Nutrition and Dietetics 75, 169-172.

Powell WS (1980) Rapid extraction of oxygenated metabolites of arachidonic acid from biological samples using octedecyl-silylsilica. Prostaglandins 20, 947-957.

Sánchez-Muniz FJ, Oubiña P, Benedí J, Ródenas S \& Cuesta C (1998) Preliminary study on platelet aggregation in postmenopausal women consuming extra virgin olive oil and high oleic acid sunflower oil. Journal of the American Oil Chemist's Society 75, 217-223.

Singleton SL \& Rossi JA (1965) Colorimetry of total phenols with phosphomolybdic phosphotungstic acid reagents. American Journal of Enology and Viticulture 16, 144-158.

Solà R, La Ville AE, Richard JL, Matta C, Burgalló MT, Girona J, Masana L \& Jacotot D (1997) Oleic acid rich diet protects 
against the oxidative modifications of high density lipoprotein. Free Radical Biology and Medicine 22, 1037-1045.

Subbiah MTR, Yunker RL \& Bydlowski SP (1991) Prostaciclinas y tromboxanos (Prostacyclins and thromboxanes). In Química Clínica. Métodos (Clinical Chemistry. Methods), 1st ed., pp. 1216-1222 [AJ Pesce and LA Kaplan, editors]. Buenos Aires, Argentina: Editorial Médica Panamericana.

Szczeklik A \& Gryglewski RJ (1980) Low density lipoproteins (LDL) are carriers for lipid peroxides and inhibit prostacyclin (PGI2) biosynthesis in arteries. Artery 7, 488-495.

Szczeklik A, Gryglewski RJ, Domagala B, Dworski R \& Basista M (1985) Dietary supplementation with vitamin E in hyperlipoproteinemias: Effects on plasma lipid peroxides, antioxidant activity, prostacyclin generation and platelet aggregability. Thrombosis and Haemostasis 52, 425-430.

Terpstra AHM, Woodward JH \& Sánchez-Muniz FJ (1981) Improved techniques for the separation of serum lipoproteins by density gradient ultracentrifugation: Visualization by prestaining and rapid separation of serum lipoproteins from small volumes of serum. Analytical Biochemistry 111, 149-157.

Trichopoulou A \& Lagiou P (1997) Healthy traditional Mediterranean diet: An expression of culture, history, and lifestyle. Nutrition Reviews 55, 383-389.

Williams CM (1997) Cardiovascular risk factors in women. Proceedings of the Nutrition Society 56, 383-391.

Yagi K (editor) (1993) Lipid peroxides, free radicals, and diseases. Active Oxygen, Lipid Peroxides, and Antioxidants39-56. Boca Raton, FL: CRC Press and Tokyo: Japan Science Society Press.

Ylä-Hertuala S, Palinski W, Rosenfeld ME, Parthasarathy S, Carew TE, Butler JS, Witztum L \& Steinberg D (1989) Evidence for the presence of oxidatively modified low density lipoprotein in atherosclerotic lesions of rabbits and man. Journal of Clinical Investigation 84, 1086-1093. 